\title{
Monitoring of adverse drug reactions to antidepressant drugs in a teaching hospital
}

\author{
Swetha Munoli ${ }^{1}$, Soumya B. Patil ${ }^{2}$
}

\begin{abstract}
${ }^{1}$ Department of Pharmacology, ESIC-MC \& PGIMSR, Bangalore, Karnataka, India ${ }^{2}$ Department of Pharmacology, Navodaya Medical College, Raichur, Karnataka, India
\end{abstract}

Received: 07 February 2017

Revised: 11 February 2017

Accepted: 06 March 2017

\section{*Correspondence to: \\ Dr. Swetha Munoli, \\ Email: \\ swethamunoli@gmail.com}

Copyright: (C) the author(s), publisher and licensee Medip Academy. This is an openaccess article distributed under the terms of the Creative Commons Attribution NonCommercial License, which permits unrestricted noncommercial use, distribution, and reproduction in any medium, provided the original work is properly cited

\begin{abstract}
Background: Adverse drug reactions (ADRs) are considered among the leading causes of morbidity and mortality. Adverse drug reactions are important determinants of non-adherence to antidepressant treatment, but their assessment is complicated by overlap with depressive symptoms and lack of reliable selfreport measures The present study was therefore undertaken to monitor the ADRs of the antidepressant in the psychiatric outpatient unit of Raichur Institute of Medical Sciences, Raichur, Karnataka, India

Methods: Study was conducted from December 2012 to November 2013, the patients on antidepressant drugs from psychiatry out- patient department (OPD) of Raichur Institute of Medical Sciences were considered for analysis. The patients were diagnosed by consultant psychiatrist. Data was collected in standard questionnaire format. All patients diagnosed with psychiatric disorder as per ICD 10 criteria and receiving treatment with antidepressant were included. Assessment of causality and severity of recorded adverse events was done using WHO assessment scale and modified Siegel and Hartwig Scale respectively.

Results: In our study 74 adverse drug reactions(ADRs) were seen among 52 cases, total 263 cases were screened.CNS and Anticholinergic side effects were most common adverse drug reactions noted. Tricyclic antidepressants (TCA) and Selective serotonin reuptake inhibitors (SSRIs) were the drugs causing maximum ADRs. Assessment of causality and severity of recorded adverse events showed possible to probable and mild to moderate severity respectively.

Conclusions: CNS and Anticholinergic side effects were most common adverse drug reactions noted. Tricyclic antidepressants (TCA) were most commonly prescribed drugs followed by Selective serotonin reuptake inhibitors (SSRIs). Tricyclic antidepressants (TCA) and Selective serotonin reuptake inhibitors (SSRIs) accounted for most of ADRs (87.8\%). Assessment of causality of recorded adverse events showed no certain cause and assessment of severity of recorded adverse events showed no severe cases.
\end{abstract}

Keywords: Antidepressants, Amitriptyline, Diarrhoea, Fluoxetine, Imipramine, Insomnia

\section{INTRODUCTION}

Pharmacovigilance the science and activities related to the detection, assessment, understanding and prevention of adverse effects or any drug related problem, is highly essential in India, where there is lack of adequate safety related data for drugs in general and psychotropic agents in particular. India seems to rate below $1 \%$ in ADR reporting, as against the world rate of $5 \% .{ }^{1}$ Depression is a common illness worldwide, with an estimated 350 million people affected. Depression is different from usual mood fluctuations and short-lived emotional responses to challenges in everyday life. Especially when long-lasting and with moderate or severe intensity, depression may become a serious health condition. It can cause the affected person to suffer greatly and function poorly at work, at school and in the family. At its worst, depression can lead to suicide. Over 800000 people die due to suicide every year. Suicide is the second leading cause of death in 15-29-year-olds. Although, there are known, effective treatments for depression, fewer than half of those affected in the world (in many countries, fewer than $10 \%$ ) receive such treatments. 
Barriers to effective care include a lack of resources, lack of trained health care providers, and social stigma associated with mental disorders. Another barrier to effective care is inaccurate assessment. In countries of all income levels, people who are depressed are often not correctly diagnosed, and others who do not have the disorder are too often misdiagnosed and prescribed antidepressants. The burden of depression and other mental health conditions is on the rise globally. A World Health Assembly resolution passed in May 2013 has called for a comprehensive, coordinated response to mental disorders at country level. ${ }^{2}$

The expanding and challenging field of psychopharmacology is constantly seeking new and improved drugs to treat psychiatric disorders. There are number of adverse drug reactions associated with these medications, which leads to noncompliance and thereby discontinuation of the therapy. Up to $70 \%$ of patients taking antidepressants are noncompliant, as a result of either missed doses or premature discontinuation. ${ }^{3}$

We conducted the study with the following objectives:

- To do surveillance and detect incidence of adverse drug reactions (ADRs) in outpatient department of Psychiatry.

- To access and analyze the ADRs according to their demographic distribution, reporting and presentations.

- To do causality and severity analysis of ADRs

\section{METHODS}

A longitudinal observational study was conducted in patients satisfying inclusion criteria attending outpatient department of psychiatry at Raichur Institute of Medical Sciences during study period from December 2012 to November 2013, patient information were recorded in CDSCO Adverse Drug Reaction reporting form Assessment of causality and severity was done using WHO assessment scale and modified Siegel and Hartwig Scale respectively. The overall incidence of ADRs was determined by taking the ratio of total number of patients who experienced ADRs to the total number of patients included in the study. The study was approved by institutional ethics committee.

\section{Inclusion criteria}

- Patient visiting the psychiatry OPD and receiving antidepressant drugs with a diagnosis of psychiatric illness as per ICD 10 criteria

- Patients above age of 12 years.

\section{Exclusion criteria}

- Diagnosed cases of mental retardation and dementia.

- Patients on stimulant drugs.

\section{RESULTS}

Overall incidence of adverse dug reaction was $19.8 \%$. Table 1 shows incidence rate of adverse drug reactions (ADRs).

Table 1: Incidence rate.

\begin{tabular}{|llll|}
\hline Name of drug & $\begin{array}{l}\text { Total no. of } \\
\text { patients }\end{array}$ & $\begin{array}{l}\text { Total } \\
\text { cases of } \\
\text { ADRs }\end{array}$ & $\begin{array}{l}\text { Incidence } \\
\text { rate }(\%)\end{array}$ \\
\hline Imipramine & 73 & 15 & 20.5 \\
\hline Amitriptyline & 76 & 13 & 17 \\
\hline Sertraline & 40 & 6 & 15 \\
\hline Fluoxetine & 50 & 10 & 20 \\
\hline Escitalopram & 10 & 3 & 30 \\
\hline Venlafaxine & 5 & 2 & 40 \\
\hline Duloxetine & 4 & 1 & 25 \\
\hline $\begin{array}{l}\text { Bupropion } \\
\text { (Atypical } \\
\text { antidepressant) }\end{array}$ & 5 & 2 & 40 \\
\hline Total & 263 & 52 & 19.8 \\
\hline
\end{tabular}

Total 263 patients receiving antidepressant drugs were screened out of which 52 cases reported ADRs. Tricyclic antidepressants (TCA) and Selective serotonin reuptake inhibitors (SSRIs) were more commonly prescribed drugs as they were available in hospital pharmacy.

Table 2: Gender wise distribution of ADR cases.

\begin{tabular}{|c|c|c|c|c|}
\hline Drug & & Male & Female & Total \\
\hline \multirow{4}{*}{ Antidepressant } & SSRI & 5 & 14 & 19 \\
\hline & $\mathrm{TCA}$ & 10 & 18 & 28 \\
\hline & SNRIs & 1 & 2 & 3 \\
\hline & Atypical & 0 & 2 & 2 \\
\hline \multicolumn{2}{|l|}{ Total (\%) } & $\begin{array}{l}16 \\
(30.8)\end{array}$ & $\begin{array}{l}36 \\
(69.2)\end{array}$ & 52 \\
\hline
\end{tabular}

SSRI-selective serotonin reuptake inhibitors, TCA-tricyclic antidepressants, SNRIs-selective serotonin-nor epinephrine reuptake inhibitors

Tricyclic antidepressants (TCA) and Selective serotonin reuptake inhibitors (SSRIs) accounted for most of ADRs $(87.8 \%)$. Table 2 shows gender wise distribution of ADR cases, ADRs were more common in female (69.2\%) compared to male $(30.8 \%)$. Table 3 shows age wise distribution of ADR cases patients between age group of 21-40 years more commonly experienced ADRs (61.5\%). Table 4 shows the nature of ADRs. Total 74 ADRs were seen in 52 cases. Insomnia, anxiety, subtle imbalance, diarrhoea, weight gain was ADR reported due to SSRIs. Dry mouth, constipation subtle imbalance and excessive sedation was seen due to TCA. Subtle imbalance, insomnia, anxiety, excessive sedation and dry mouth were ADR reported due to selective serotonin-nor epinephrine reuptake inhibitors (SNRIs). Subtle imbalance, insomnia and dry mouth were ADR reported due to atypical antidepressant (bupropion). 
Table 3: Age wise distribution of ADR cases.

\begin{tabular}{|lllllll|}
\hline Drug & & $\mathbf{1 2}-<\mathbf{2 1}$ & $\mathbf{2 1 - < 4 1}$ & $\mathbf{4 1}-<\mathbf{6 1}$ & $\mathbf{6 1}$ & Total \\
\hline \multirow{4}{*}{ Antidepressants } & SSRI & 3 & 12 & 4 & 0 & 19 \\
\cline { 2 - 7 } & TCA & 2 & 16 & 9 & 1 & 28 \\
\cline { 2 - 7 } & SNRIs & 0 & 2 & 1 & 0 & 3 \\
\cline { 2 - 7 } Total & Atypical & 0 & 2 & 0 & 0 & 2 \\
\hline
\end{tabular}

Table 4: Nature of ADRs.

\begin{tabular}{|c|c|c|c|c|}
\hline Drug & & Drugs & No of ADRs & Adverse reactions \\
\hline \multirow{8}{*}{ Antidepressants } & \multirow{3}{*}{ SSRI } & Sertraline & 10 & Insomnia, subtle imbalance,diarrhoea \\
\hline & & Fluoxetine & 12 & Insomnia ,anxiety, diarrhoea, weight gain \\
\hline & & Escitalopram & 5 & Insomnia, weight gain \\
\hline & \multirow[t]{2}{*}{ TCA } & Imipramine & 20 & $\begin{array}{l}\text { Excessive sedation, subtle imbalance, dryness of mouth, } \\
\text { constipation }\end{array}$ \\
\hline & & Amitriptyline & 18 & dryness of mouth , constipation, subtle imbalance \\
\hline & \multirow{2}{*}{ SNRIs } & Duloxetine & 2 & Excessive sedation, dryness of mouth \\
\hline & & Venlafaxine & 4 & Insomnia, subtle imbalance, anxiety, dryness of mouth \\
\hline & Atypical & Bupropion & 3 & Insomnia ,subtle imbalance, dryness of mouth \\
\hline \multicolumn{3}{|l|}{ Total } & 74 & 74 \\
\hline
\end{tabular}

Table 5: ADR of different system.

\begin{tabular}{|c|c|c|c|c|c|c|c|c|c|c|}
\hline \multirow{2}{*}{ Drug } & & \multicolumn{4}{|c|}{ CNS } & \multicolumn{2}{|c|}{ ACSE } & GIT & WG & Total (\%) \\
\hline & & ES & Anxiety & Insomnia & SI & DM & СТP & \multicolumn{3}{|l|}{ Diarrhoea } \\
\hline \multirow{4}{*}{$\begin{array}{l}\text { Anti- } \\
\text { depressants }\end{array}$} & SSRI & - & 2 & 3 & 5 & - & - & 10 & 7 & $27(36.4)$ \\
\hline & TCA & 6 & - & - & 7 & 13 & 12 & - & - & $38(51.3)$ \\
\hline & SNRIs & 1 & 1 & 1 & 1 & 2 & - & - & - & $6(8.1)$ \\
\hline & Atypical & - & - & 1 & 1 & 1 & - & - & - & $3(4)$ \\
\hline Total & & 7 & 3 & 5 & 14 & 16 & 12 & 10 & 7 & 74 \\
\hline
\end{tabular}

ES-excessive sedation, SI-subtle imbalance, CNS-central nervous system, ACSE-anticholinergic side effects, DM-dryness of mouth, CTP-contstipation, GIT-gastro intestinal tract, WG-weight gain

Table 6: Causality assessment of ADRs (WHO scale).

\begin{tabular}{|llllll|}
\hline Drug & & Certain & Probable & Possible & Total \\
\hline \multirow{4}{*}{ Antidepressants } & SSRI & 0 & 2 & 17 & 19 \\
\cline { 2 - 6 } & TCA & 0 & 4 & 24 & 28 \\
\cline { 2 - 6 } & SNRIs & 0 & 0 & 3 & 3 \\
\cline { 2 - 6 } Total & Atypical & 0 & 0 & 2 & 2 \\
\hline
\end{tabular}

Table 7: Severity of ADR cases.

\begin{tabular}{|llllll|}
\hline Drug & & MILD & MODERATE & SEVERE & Total \\
\hline \multirow{4}{*}{ Antidepressants } & SSRI & 15 & 4 & 0 & 19 \\
\cline { 2 - 6 } & TCA & 21 & 7 & 0 & 28 \\
\cline { 2 - 6 } & SNRIs & 2 & 1 & 0 & 3 \\
\cline { 2 - 6 } Total & Atypical & 1 & 1 & 0 & 2 \\
\hline
\end{tabular}

Table 5 shows distribution of ADR according to different system, ADRs of central nervous system (39\%) and anticholinergic side effects $(38 \%)$ were more common followed by diarrhoea $(13.5 \%)$ and weight gain $(9.4 \%)$. 
Table 6 shows causality assessment of ADRs using WHO scale. Most of cases were possible $(88.5 \%)$ in their causality category. $11.5 \%$ cases were in probable category and no certain cases were seen. Table 7 shows severity of ADR cases. Severity was assessed using modified Siegel and Hartwig Scale. $75 \%$ cases were mild and $25 \%$ cases were moderate in their severity and no severe cases were seen.

\section{DISCUSSION}

Adverse drug reactions remain a common clinical problem since they can mimic many diseases and cause significant morbidity and mortality. Judicious prescribing is important to minimize their occurrence. Spontaneous reporting continues to play an important role in pharmacovigilance and the value of vigilant clinical observation and well-documented reports of suspicions of a causal link cannot be underestimated. Many national reporting schemes have developed considerable experience and expertise over many years and have large ADR databases, which are national assets. Adverse reactions to medicines are a common, yet often preventable cause of illness, disability and even death.

Present study was planned for detection of incidence rate, assessment, classification and causality analysis of Adverse Drug Reactions (ADRs) to antidepressant drugs in patients of psychiatry OPD in RIMS (Raichur Institute of Medical Sciences) hospital. In our study 74 adverse drug reactions (ADRs) were seen among 52 cases, total 263 cases were screened.

ADR cases of antidepressant drugs were voluntarily and intensively reported by treating psychiatrist and resident doctor of psychiatry department in RIMS hospital during the study period of one year from December 2012 to November 2013. The information thus gathered about ADRs to antidepressant drugs were compiled and analyzed to study incidence, their age and gender wise distribution, causality analysis, nature, type and severity.

Overall incidence of adverse dug reaction was $19.8 \%$. Incidence of ADR was less compared to previous study by Lucca et al where prevalence of ADR was $42.4 \%$ and a study by Swati et al where prevalence was $26.87 \%$. $^{4,5}$ Incidence of ADR was more common in female $36(69.2 \%)$ similar to study by Mukherjee et al and majority of patients $32(61.5 \%)$ were in $21-40$ age group similar to previous study. ${ }^{5-7}$

ADRs of Central nervous system (29), anticholinergic side effects (28) and diarrhoea (10) were most common ADRs noted in our study. A study by Lucca et al showed GIT as most common organ system affected by ADRs. ${ }^{4}$ Dry mouth was most common ADRs noted in our study. This finding is similar to study by Lucca et al. ${ }^{4}$ Tricyclic antidepressants (TCA) and Selective serotonin reuptake inhibitors (SSRIs) accounted for most of ADRs (87.8\%) compared to SNRIs and atypical antidepressants (12.2\%), similar results were seen in a study by Swati et al. ${ }^{5}$ This could be attributed to increased use of these drugs as they were available in the hospital pharmacy. Tricyclic antidepressants (TCA) were more commonly prescribed and were most common drug implicated in causing ADRs.

Dry mouth and constipation were more commonly seen with Tricyclic antidepressants (TCA), diarrhoea and weight gain was seen in patients who were on Selective serotonin reuptake inhibitors (SSRIs). ADRs of Central nervous system and dry mouth were ADR reported due to selective serotonin-nor epinephrine reuptake inhibitors $(8.1 \%)$. Subtle imbalance, Insomnia and dry mouth were ADR reported due to bupropion (4\%).

Causality assessment was done using WHO assessment scale, no certain causes were seen since in cases where dechallenge was done, rechallenge was not attempted with the offending drug. This is in contrast to a Brazilian study where 24 cases were found to be definite after rechallenge was attempted. ${ }^{8}$ All ADRs reported were of mild to moderate severity. Study in India by Jose $\mathbf{J}$ et alshowed mild and moderate reactions accounted for $50.5 \%$ and $43.9 \%$ respectively. ${ }^{9}$ Grohmann $\mathrm{R}$ et al conducted study in Germany in 2004 and showed that severe ADRs due to psychopharmacological agents occurred in $1.4 \%$ of exposed patients. ${ }^{10}$

\section{CONCLUSION}

Overall incidence of adverse dug reaction was $19.8 \%$. ADRs of Central nervous system (CNS) and Anticholinergic side effects were most common adverse drug reactions noted. Tricyclic antidepressants (TCA) were most commonly prescribed drugs followed by Selective serotonin reuptake inhibitors (SSRIs).

Tricyclic antidepressants (TCA) and Selective serotonin reuptake inhibitors (SSRIs) accounted for most of ADRs $(87.8 \%)$. This study adds to the existing information on ADRs to antidepressant medication. Psychiatrists should actively participate in establishment of pharmacovigilance programme. This will help to gain more insight into the pattern of ADRs to all psychopharmacological agents to improve the quality of patient care by ensuring safer use of drugs.

\section{ACKNOWLEDGEMENTS}

Authors are grateful to the faculty members of psychiatry department and Dean cum Director of Raichur Institute of Medical Sciences, RIMS Govt. Medical College, Raichur, Karnataka for providing necessary research facilities.

Funding: No funding sources Conflict of interest: None declared

Ethical approval: The study was approved by the Institutional Ethics Committee 


\section{REFERENCES}

1. Lingeswaran A, Shetty H, Lahon K, Paramel A, Sharma G. Pharmacovigilance on olanzapine. Indian J Pharmacol. 2010;42:252-3.

2. World Health Organization. Mental health. Fact sheet on Depression. Available from: http://www.who.int/mediacentre/factsheets/fs369/en/

3. Richelson E. Interaction of antidepressants with neurotransmitter transporters and receptors and their clinical relevance. J Clin Psychiatry. 2003;64:5-12.

4. Lucca JM, Madhan R, Gurumurthy P, Dushad R. A prospective observational study to evaluate safety reporting of antidepressants at a tertiary care hospital in India. Indian J Pharmacol. 2014;46:543-6.

5. Mishra S, Swain TR, Mohanty M. Adverse drug reaction monitoring of antidepressants in the psychiatry outpatients department of a tertiary care teaching hospital. J Clin Diagn Res. 2013;7:1131-4.

6. Mukherjee S, Sen S, Chatterjee SS, Era N, Ghosal M, Tripathi SK. Adverse drug reaction monitoring of antidepressants in the psychiatry outpatient department at a tertiary care teaching hospital in
India: a cross-sectional observational study. Eur $\mathbf{J}$ Psychol Educ Studies. 2015;2:14-9.

7. Solanke B, Mahatme MS, Dakhale G, Hiware S, Shrivastava M, Waradkar P. Adverse drug reaction profile at psychiatry out-patient department of a tertiary referral centre in Central India. Int $\mathrm{J}$ Basic Clin Pharmacol. 2013;2:341-3.

8. Carlini EL, Nappo SA. The pharmacovigilance of psychoactive agents in Brazil. Rev Bras Psiquiatr. 2003;25:200-5

9. Jose J, Rao PGM. Pattern of adverse drug reactions notified by spontaneous reporting in an Indian tertiary care teaching hospital. Pharmacologic Res. 2006;54:226-33.

10. Grohmann R, Hippius H, Helmchen H, Ruther E, Schmidt LG. The AMPU study for drug surveillance in psychiatry-a summary of inpatient data. Pharmacopsychiatry. 2004:37:S16-26.

Cite this article as: Munoli S, Patil SB. Monitoring of adverse drug reactions to antidepressant drugs in a teaching hospital. Int J Basic Clin Pharmacol 2017;6:933-7. 